\title{
THE PUPILLARY CHANGES IN THE HOLMES-ADIE SYNDROME
}

\author{
BY
}

\author{
G. F. M. RUSSELL \\ From the Neurological Unit, the Northern General Hospital, Edinburgh
}

Widely varying pupillary abnormalities are in clinical practice often grouped under the heading of the Holmes-Adie syndrome. Adie (1932) described the complete form of the disorder as comprising the typical tonic pupil, with its characteristic delayed reaction to convergence and the loss of some of the tendon reflexes, whereas in the incomplete form he included those cases in which the reflexes were normal, or the pupillary disturbance was atypical (as in the fixed pupil of ophthalmoplegia interna). Alajouanine and Morax (1938) state that no two pupils are identical, and they agree with Lowenstein and Friedman (1942) that between the typical tonic and syphilitic pupils all kinds of intermediary changes may be seen. They suggest, moreover, that pupillotonia is not a fixed condition, but may follow on a paralysed pupil and even precede an Argyll Robertson pupil. A similar evolution in which the fixed pupil of ophthalmoplegia interna becomes typically tonic is described by Rothmann (1903), Axenfeld (1919), Reitsch (1925), and Adie (1932). Adie, on the other hand, says that the tonic pupil may suddenly become dilated and fixed, but there are no definite recorded instances of this. Holmes (1931) describes the course of events in a patient who, over a period of 17 years, developed anisocoria, then a left pupillary lesion, and finally a lesion of the right pupil.

In order to unify the many pupillary variants and to understand how the disturbance develops, studies were made of the effect of procaine block of the stellate ganglion and of the reaction of the pupil to drugs. In this way, additional light was shed on the pathogenesis of the lesion.

\section{Case Reports}

The clinical findings are summarized in Table I. Four cases merit more detailed description, because they illustrate the multiplicity of pupillary abnormalities encountered in the syndrome.

Case 1.-A young single woman suddenly sensed a blurring of the vision of the left eye, and on looking in a mirror she noticed that the left pupil was somewhat larger than the right. Next morning she found that the left pupil had enlarged even further, and thereafter it remained fully dilated. Examination two months later revealed a large pupil, fixed to light and convergence, with paralysis of accommodation in the same eye and a reduction of visual acuity to J.7. Eleven months after the onset of symptoms she was again able to read J.1, but accommodation from distant to close vision required 13 seconds. The pupil still failed to respond to both light and convergence, and the tendon reflexes remained normal. In view of the development of delayed accommodation this case of ophthalmoplegia interna was included in the series.

Case 2.-This young girl had suffered from an intermittent divergent heterotropia since the age of 5 , but had compensated for it fairly well until now. During the course of her clerical work she suddenly noticed a dimness in the vision of the left eye, and her attention was drawn to an enlargement of the pupil on that side. Thereafter, the tendency to divergence of the eyes became accentuated and she had to close the left eye while at work to avoid troublesome diplopia. Examination showed a left tonic pupil and absent knee and ankle jerks. Sixteen months later (October 2, 1955), while she was reading, the right eye became blurred, and to continue reading she had to close that eye and revert to fixation with the left eye. She was examined within two days of this relapse, and it was found that the right pupil was enlarged and reacted poorly to light and accommodation. Visual acuity on that side remained at $\mathrm{J} .1$, but 15 seconds were required for accommodation from a distance, and the near point was $25 \mathrm{~cm}$. All tendon reflexes were absent except the right biceps jerk. Frequent examinations over the next few days revealed progressive paralysis of accommodation. On October 6 she could only read J.3 with the right eye, and on October 15 vision was restricted to J.8 and the near point increased to $58 \mathrm{~cm}$., while distant vision remained relatively unaltered. At the same time the pupil became further enlarged, fixed to light, and only slightly responsive to accommodation. Her heterophoria was now decompensated and she developed an intermittent divergent squint for close vision and a convergence insufficiency. With a plus 3 lens in front of the right eye she could see J.1, but the left eye became divergent, whereas without glasses she depended on the left eye and the right eye deviated outwards.

Case 10.-A man of 34 had attended an ophthalmic department in September, 1954, complaining of a 
TABLE I

SUMMARY OF CLINICAL FINDINGS

\begin{tabular}{|c|c|c|c|c|c|c|c|c|c|c|c|c|c|c|c|}
\hline $\begin{array}{l}\dot{0} \\
z \\
\tilde{g} \\
\tilde{J}\end{array}$ & 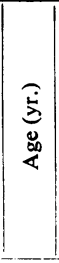 & 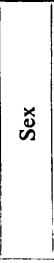 & History & Features of Pupil(s) & 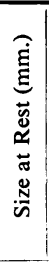 & 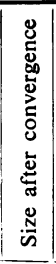 & 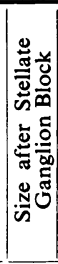 & 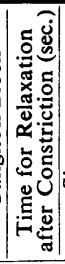 & 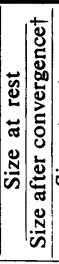 & 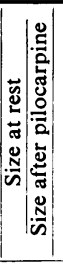 & 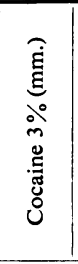 & 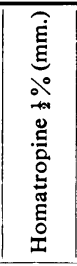 & 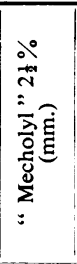 & $\begin{array}{l}\text { Tendon } \\
\text { Reflexes }\end{array}$ & 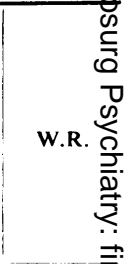 \\
\hline 1 & 33 & F & $\begin{array}{l}\text { Sudden } \\
\text { vision } \\
1954)\end{array}$ blurring of & $\begin{array}{l}\text { Fixed irregular pupil with } \\
\text { tonic accommodation }\end{array}$ & 9 & 9 & 9 & - & 1 & $1 \cdot 13$ & Nil & Nil & Nil & Normal & $\begin{array}{l}\text { Negative } \\
\text { in C.S.E } \\
\text { and bloळ }\end{array}$ \\
\hline 2 & 25 & $\mathbf{F}$ & $\begin{array}{l}\text { Sudden blurring of } \\
\text { vision of left eye in } \\
1954 \text {; similar occur- } \\
\text { rence in right eye } \\
\text { in } 1955\end{array}$ & $\begin{array}{l}\text { Bilateral changes affect- } \\
\text { ing both pupil and } \\
\text { accommodation; para- } \\
\text { lytic on the right and } \\
\text { tonic on the left }\end{array}$ & $\begin{array}{l}\text { R. } \\
5 \frac{1}{2} \\
\mathbf{L} . \\
8\end{array}$ & $\begin{array}{l}4 \frac{1}{2} \\
2 \frac{1}{2}\end{array}$ & $4 \frac{1}{2}$ & $\begin{array}{l}11 \\
40\end{array}$ & $\begin{array}{l}1 \cdot 2 \\
2 \cdot 5\end{array}$ & $\begin{array}{c}1 \cdot 5 \\
3 \cdot 0\end{array} \mid$ & $\begin{array}{l}\rightarrow 7 \frac{1}{2} \\
\rightarrow 10\end{array}$ & $\begin{array}{l}\rightarrow 8 \\
\rightarrow 9\end{array}$ & $\begin{array}{l}\rightarrow 5 \\
\rightarrow 4\end{array}$ & $\begin{array}{l}\text { All } \\
\text { absent } \\
\text { except } \\
\text { right } \\
\text { B.J. }\end{array}$ & $\begin{array}{l}\text { Negative } \overline{\bar{\rho}} \\
\text { in C.S.F } \\
\text { and } \\
\text { blood } \frac{\mathbb{D}}{0}\end{array}$ \\
\hline 3 & 56 & $\mathbf{F}$ & $\begin{array}{l}\text { Incidental finding; epi- } \\
\text { sode of blurred vision } \\
\text { in } 1924\end{array}$ & $\begin{array}{l}\text { Oval tonic pupil with } \\
\text { normal accommoda- } \\
\text { tion }\end{array}$ & 5 & $3 \frac{1}{2}$ & $3 \frac{1}{2}$ & 12 & $1 \cdot 3$ & $1 \cdot 8$ & $\rightarrow 5$ & $\rightarrow 7$ & $\rightarrow 3 \frac{1}{2}$ & $\begin{array}{l}\text { Absent } \\
\text { T.J.s, } \\
\text { K.J.s, } \\
\text { A.J.s }\end{array}$ & $\begin{array}{r}\text { Negative- } \\
\text { in blood } \\
\frac{\overrightarrow{1}}{\omega}\end{array}$ \\
\hline 4 & 34 & $\mathbf{F}$ & $\begin{array}{l}\text { Incidental finding } \\
(1955)\end{array}$ & $\begin{array}{l}\text { Bilateral irregular tonic } \\
\text { pupils with tonic ac- } \\
\text { commodation on left }\end{array}$ & $\begin{array}{l}\text { R. } \\
5 \\
\text { L. } \\
4\end{array}$ & $\begin{array}{l}3 \frac{1}{2} \\
3\end{array}$ & - & $\begin{array}{r}4 \\
11\end{array}$ & $\begin{array}{l}- \\
1 \cdot 4\end{array}$ & - & $\begin{array}{l}\rightarrow 6 \\
\rightarrow 5 \frac{1}{2}\end{array}$ & $\begin{array}{l}\rightarrow 7 \\
\rightarrow 5 \frac{1}{2}\end{array}$ & $\begin{array}{l}\mathrm{Nil} \\
\mathrm{Nil}\end{array}$ & $\begin{array}{l}\text { Absent } \\
\text { T.J.s. } \\
\text { K.J.s, } \\
\text { A.J.s }\end{array}$ & $\begin{array}{r}\text { Negative } \\
\text { in blood } \\
\frac{7}{3} \\
\end{array}$ \\
\hline 5 & 36 & $\mathbf{F}$ & $\begin{array}{c}\text { Incidental finding } \\
(1954)\end{array}$ & $\begin{array}{l}\text { Irregular tonic pupil; } \\
\text { normal accommodation }\end{array}$ & $3 \frac{1}{2}$ & $2 \frac{1}{2}$ & - & 22 & $1 \cdot 4$ & 1.8 & $\rightarrow 4 \frac{1}{2}$ & $\rightarrow 5$ & $\overrightarrow{\rightarrow 2 \frac{1}{2}}$ & $\begin{array}{l}\text { All } \\
\text { absent }\end{array}$ & $\begin{array}{l}\text { Negativeo } \\
\text { in blood }\end{array}$ \\
\hline 6 & 56 & $\mathbf{F}$ & $\begin{array}{l}\text { Incidental finding } \\
\text { (1956) }\end{array}$ & $\begin{array}{l}\text { Bilateral irregular pupils; } \\
\text { normal accommoda- } \\
\text { tion }\end{array}$ & $\begin{array}{l}\text { R. } \\
3 \\
\text { L. } \\
3 \frac{1}{2}\end{array}$ & $\begin{array}{l}2 \\
2\end{array}$ & - & $\begin{array}{r}18 \\
8\end{array}$ & $\begin{array}{l}1.5 \\
-\end{array}$ & $\begin{array}{l}1 \cdot 8 \\
-\end{array}$ & $\begin{array}{l}\rightarrow 4 \frac{1}{2} \\
\rightarrow 5\end{array}$ & - & - & $\begin{array}{l}\text { Absent } \\
\text { A.J.s }\end{array}$ & 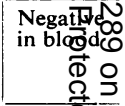 \\
\hline 7 & 69 & $\mathbf{F}$ & $\begin{array}{l}\text { Incidental finding } \\
(1955)\end{array}$ & $\begin{array}{l}\text { Bilateral changes; pupils } \\
\text { irregular; accommoda- } \\
\text { tion slow on left }\end{array}$ & $\begin{array}{l}\mathrm{R} . \\
3 \\
\mathrm{~L} . \\
2 \mathrm{i}\end{array}$ & $\begin{array}{l}2 \\
2\end{array}$ & - & $\begin{array}{r}6 \\
20\end{array}$ & $\begin{array}{c}- \\
1 \cdot 5\end{array}$ & - & $\begin{array}{l}\rightarrow 3 \frac{1}{2} \\
\rightarrow 5\end{array}$ & $\begin{array}{l}\rightarrow 6 \\
\rightarrow 5\end{array}$ & $\begin{array}{l}\rightarrow 2 \frac{1}{2} \\
\rightarrow 1 \frac{1}{2}\end{array}$ & $\begin{array}{l}\text { T.J.s, } \\
\text { K.J.s, } \\
\text { A.J.s } \\
\text { absent; } \\
\text { S.J.s } \\
\text { sluggish }\end{array}$ & 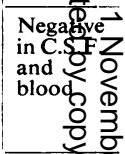 \\
\hline 8 & 19 & $\mathbf{F}$ & $\begin{array}{l}\text { Sudden onset of pain } \\
\text { in the right eye } \\
\text { (1955); enlargement } \\
\text { of the left pupil noted } \\
\text { at that time }\end{array}$ & $\begin{array}{l}\text { Bilateral irregular pupils } \\
\text { with more markedly } \\
\text { tonic reaction on the } \\
\text { left; accommodation } \\
\text { normal }\end{array}$ & $\begin{array}{l}\mathbf{R} . \\
3 \frac{1}{2} \\
\mathbf{L} \\
7 \frac{1}{2}\end{array}$ & $\begin{array}{l}2 \frac{1}{2} \\
4 \frac{1}{2}\end{array}$ & - & $\begin{array}{r}5 \\
20\end{array}$ & $\begin{array}{c}- \\
1 \cdot 5\end{array}$ & - & $\begin{array}{l}\rightarrow 4 \frac{1}{2} \\
\rightarrow 8\end{array}$ & $\begin{array}{l}\rightarrow 7 \\
\rightarrow 8\end{array}$ & $\begin{array}{l}\rightarrow 2 \frac{1}{2} \\
\rightarrow 4 \frac{1}{2}\end{array}$ & $\begin{array}{l}\text { Absent } \\
\text { K.J.s, } \\
\text { A.J.s }\end{array}$ & 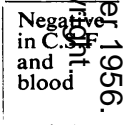 \\
\hline 9 & 55 & $\mathbf{F}$ & $\begin{array}{l}\text { Incidental finding } \\
\text { (1955) }\end{array}$ & $\begin{array}{l}\text { Bilateral irregular tonic } \\
\text { pupils; delayed accom- } \\
\text { modation }\end{array}$ & $\begin{array}{l}\mathrm{R} . \\
4 \frac{1}{2} \\
\mathrm{~L} . \\
5\end{array}$ & $\begin{array}{l}3 \\
2 \frac{1}{2}\end{array}$ & $\begin{array}{l}3 \\
- \\
\end{array}$ & $\begin{array}{r}20 \\
7 \\
\end{array}$ & $\begin{array}{l}1 \cdot 5 \\
- \\
\end{array}$ & $\begin{array}{l}2 \cdot 3 \\
- \\
\end{array}$ & $\begin{array}{l}\rightarrow 7 \frac{1}{2} \\
\rightarrow 6 \frac{1}{2} \\
\end{array}$ & $\begin{array}{l}\rightarrow 7 \\
\rightarrow 7\end{array}$ & $\rightarrow 4$ & $\begin{array}{l}\text { All } \\
\text { absent }\end{array}$ & $\begin{array}{l}\text { Negativs } \\
\text { in C.S.F } \\
\text { and } \\
\text { blood } \bar{\Xi}\end{array}$ \\
\hline 10 & 35 & $\mathbf{M}$ & $\begin{array}{l}\text { Sudden onset of blurred } \\
\text { vision }\end{array}$ & $\begin{array}{l}\text { Fixed left pupil (1954); } \\
\text { one year later developed } \\
\text { a tonic pupil and slow } \\
\text { accommodation }\end{array}$ & 5 & $2 \frac{1}{2}$ & 3 & 20 & 1.9 & $2 \cdot 3$ & $\rightarrow 7 \frac{1}{2}$ & $\rightarrow 9$ & - & $\begin{array}{l}\text { Absent } \\
\text { S.J.s, } \\
\text { A.J.s; } \\
\text { K.J.s } \\
\text { sluggish }\end{array}$ & $\begin{array}{r}\begin{array}{r}\text { Negative } \\
\text { in bloodळ } \\
\text { Q }\end{array} \\
\text { 을 }\end{array}$ \\
\hline 11 & 49 & $\mathbf{M}$ & $\begin{array}{l}\text { Incidental finding } \\
\text { (1955) }\end{array}$ & $\begin{array}{l}\text { Irregular tonic pupil; } \\
\text { delayed accommoda- } \\
\text { tion on the right }\end{array}$ & 7 & 3 & $2 \frac{1}{2}$ & 45 & 1.9 & $2 \cdot 3$ & $\rightarrow 8$ & $\rightarrow 8$ & $\rightarrow 4 \frac{1}{2}$ & $\begin{array}{l}\text { A.J.s } \\
\text { absent }\end{array}$ & $\begin{array}{l}\text { Negative } \\
\text { in C.S. } \\
\text { and blo }\end{array}$ \\
\hline 12 & 37 & $F$ & $\begin{array}{l}\text { Incidental finding } \\
\text { (1956) }\end{array}$ & $\begin{array}{l}\text { Bilateral irregular tonic } \\
\text { pupils; marked delay } \\
\text { of accommodation }\end{array}$ & $\begin{array}{l}\mathrm{R} . \\
4 \\
\mathrm{~L} \\
5 \frac{1}{2}\end{array}$ & $\begin{array}{l}2 \\
3\end{array}$ & $\begin{array}{l}2 \\
-\end{array}$ & $\begin{array}{l}40 \\
10\end{array}$ & $\begin{array}{l}2 \cdot 2 \\
-\end{array}$ & $\begin{array}{l}2 \cdot 5 \\
-\end{array}$ & $\begin{array}{l}\rightarrow 5 \frac{1}{2} \\
\rightarrow 7\end{array}$ & $\begin{array}{l}\rightarrow 5 \frac{1}{2} \\
\rightarrow 7\end{array}$ & $\begin{array}{l}\rightarrow 3 \\
\rightarrow 4 \frac{1}{2}\end{array}$ & $\begin{array}{l}\text { Absent } \\
\text { B.J.s, } \\
\text { T.J.s, } \\
\text { K.J.s, } \\
\text { A.J.s }\end{array}$ & $\begin{array}{r}\text { Negative } \\
\text { in blood? } \\
\text { 음 } \\
\text { 을 }\end{array}$ \\
\hline 13 & 36 & $\mathbf{F}$ & $\begin{array}{l}\text { Incidental finding } \\
\text { (1955) }\end{array}$ & $\begin{array}{l}\text { Bilateral irregular tonic } \\
\text { pupils; normal accom- } \\
\text { modation }\end{array}$ & $\begin{array}{l}\mathbf{R} \\
3 \frac{1}{2} \\
\mathbf{L} \\
5 \frac{1}{2}\end{array}$ & $\begin{array}{l}2 \\
2\end{array}$ & - & $\begin{array}{l}30 \\
48\end{array}$ & $\begin{array}{l}- \\
2 \cdot 2\end{array}$ & $2 \cdot 7$ & $\begin{array}{l}\rightarrow 5 \frac{1}{2} \\
\rightarrow 7\end{array}$ & $\begin{array}{l}\rightarrow 5 \frac{1}{2} \\
\rightarrow 7\end{array}$ & $\begin{array}{l}\rightarrow 3 \\
\rightarrow 2 \frac{1}{2}\end{array}$ & $\begin{array}{l}\text { Absent } \\
\text { K.J.s, } \\
\text { A.J.s, } \\
\text { and } R \text {. } \\
\text { B.J., } \\
\text { S.J." }\end{array}$ & $\begin{array}{l}\begin{array}{l}\text { Negative } \\
\text { in C.S.F } \\
\text { and } \\
\text { blood }\end{array} \\
\\
\end{array}$ \\
\hline 14 & 51 & $\mathbf{M}$ & $\begin{array}{l}\text { Incidental finding } \\
(1955)\end{array}$ & $\begin{array}{l}\text { Oval tonic pupil with } \\
\text { slow accommodation; } \\
\text { ipsilateral ptosis and } \\
\text { facial anhidrosis }\end{array}$ & 4 & $3 \frac{1}{2}$ & 4 & 10 & * & * & Nil & $\rightarrow 8$ & $\mathrm{Nil}$ & $\begin{array}{l}\text { A.J.s } \\
\text { sluggish }\end{array}$ & $\begin{array}{l}\text { Negativ? } \\
\text { in C.S.F首. } \\
\text { and } \\
\text { blood N }\end{array}$ \\
\hline
\end{tabular}


sensation of glare in the left eye which had developed suddenly. At this time the left pupil was found to be dilated and fixed to light and convergence. When seen 16 months later, his symptoms had subsided and the pupil was irregular and typically tonic, taking 20 seconds to dilate after relaxation of convergence. During a medical examination in 1939 it had been noted that the tendon reflexes in the legs were sluggish or absent.

Case 14.-A 51-year-old dock worker was admitted to hospital with pneumonia, where it was noted that he had a left-sided ptosis and an oval enlarged pupil which reacted only slightly and sluggishly to light and convergence. He maintained that the ptosis had been present all his life and that his father, now dead, had also had a drooping upper eyelid. Sweat tests showed anhidrosis on the left side of the face, and the ptosis was therefore ascribed to a lesion of unknown causation in the sympathetic pathway proximal to the bifurcation of the common carotid artery. Clearly, this could not alone account for an irregular, enlarged, and poorly reacting pupil. The following evidence was obtained for including the patient in the series of tonic pupils: pupillary dilatation to $6 \frac{1}{2} \mathrm{~mm}$. resulted when he was kept in total darkness for 40 minutes, and after exposure to bright daylight the pupil took three minutes to return to a diameter of $3 \frac{1}{2} \mathrm{~mm}$. This was, therefore, a rare example of the natural occurrence of a tonic pupil with a sympathetic lesion.

Many of the clinical features emphasized by Graveson (1949) were encountered in this series. Irregularity of the pupils was a constant finding, and bilateral pupillary changes were often present (Cases 2, 4, 6, 7, 8, 9, 12, and 13). In Cases 4, 7, and 8 , the second pupil showed only slightly delayed relaxation $(4,6$, and 5 seconds respectively), but these times were held to be significant in view of the accompanying irregular pupillary outline. The abnormal pupil was not necessarily enlarged: in nine instances it measured $4 \mathrm{~mm}$. or less in diameter, and in one it was only $2 \frac{1}{2} \mathrm{~mm}$. Adie suggests that the stimulus of convergence is stronger than that of light, quite apart from whether or not the nervous pathways conveying these reactions are anatomically distinct. This is certainly borne out by the behaviour of abnormal pupils in which constriction to convergence is always greater than constriction to light or accommodation. An exception to this rule may be found in patients with an insufficiency of convergence, often associated with an heterophoria, as in Case 2. The effect of weeping on the tonic pupil was observed in one patient who was depressed (Case 9). As noted by Adie, Holmes, and Graveson, crying caused pupillary constriction followed by the slow relaxation. Adie (1932) and Kennedy, Wortis, Reichard, and Fair (1938) say that loss of the upper limb reflexes is uncommon, but it was found in nine of the 14 patients in- vestigated, the triceps jerks being most commonly affected. In two patients, moreover, all the reflexes were absent.

There is often a more than superficial similarity between Holmes-Adie and Argyll Robertson pupils. Confusion is most likely to arise when the pupils are small, for a delay in constriction and dilatation is naturally more difficult to detect when the range of movement is slight. This problem remains one in the interpretation of signs, the pathogenesis and aetiology of the two kinds of pupils being probably quite distinct. Certainly there is no evidence of a syphilitic basis in any of the cases reported in this series.

\section{Methods of Investigation}

Procaine Block of the Stellate Ganglion.-This was done on 11 abnormal pupils in 10 patients to find out whether an over-activity or a lesion of the sympathetic nervous system played a part in the pathogenesis of the condition. In over-activity, a procaine block of the sympathetic nervous system would nullify at least some of the anomalies of the tonic pupil, so that special attention was directed to the resulting change in pupillary size and the effect on pupillotonia. In a lesion of the sympathetic nervous system, on the other hand, further interruption by procaine block would not cause any alteration in the size of the pupil. The stellate ganglion on the side of the abnormal pupil was infiltrated with $5 \mathrm{ml}$. of $1 \%$ procaine hydrochloride according to the method advocated by Moore (1954), using an anterior cervical approach. (There are only two records in the literature of the effect of a stellate ganglion block on the Holmes-Adie pupil (Barré and Klein, 1934; Alajouanine and Morax, 1938) and these are at variance with each other.)

In the 11 pupils tested, pupillary constriction occurred to a widely varying degree (Table I and Fig. 1). Where the reduction in the size of the pupil was slight or absent, the effectiveness of the procaine block was ascertained by the development of ptosis, conjunctival injection, and facial anhidrosis. When necessary, a sweat test was performed immediately after the procaine injection, using quinizarin 2:6 disulphonic acid powder (Burroughs and Wellcome) as an indicator. In Case 1, for instance, facial anhidrosis was demonstrated when the pupil remained fully dilated. This result was the same as that found with stellate ganglion block in normal patients where the pupil is paralysed by $2 \%$ homatropine. Pupillary constriction after interruption of the sympathetic depends on the action of functioning parasympathetic fibres, and its extent is thus a measure of the degree of parasympathetic preservation, which can be expressed by the ratio

$$
\begin{aligned}
& \text { Size of the pupil at rest } \\
& \text { Size of the pupil after stellate ganglion block }
\end{aligned}
$$

Fig. 1 shows that the size of the pupil reached after the procaine block matched closely that resulting from convergence under resting conditions, so long as this movement could be maintained adequately. It is simpler, 


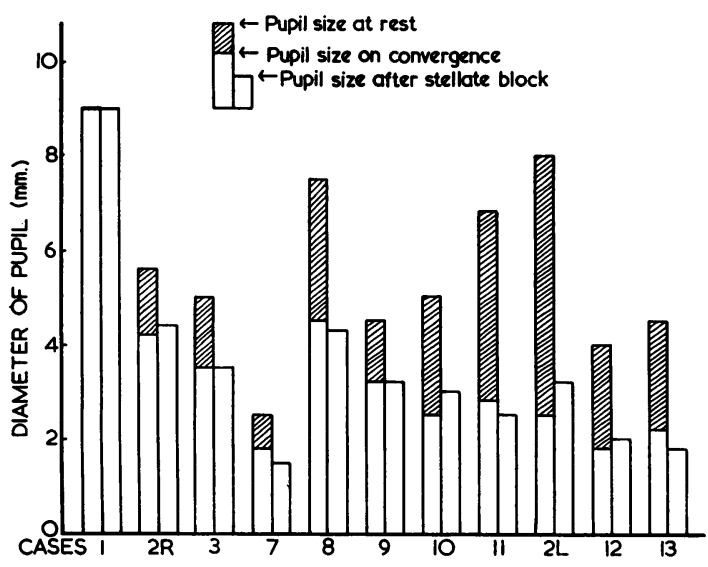

FIG. 1.-For each patient, the size of the pupil reached after stellate ganglion block approximates to that resulting from convergence under resting conditions (measured immediately before the block).

therefore, to assess parasympathetic sparing by the fraction

Size of the pupil at rest

Size of the pupil after convergence

The slowest reacting pupils showed the greatest degree of miosis after stellate ganglion block. The range of contraction in response to convergence became diminished thereafter, so that timing by the naked eye of constriction and relaxation was rendered extremely difficult. Accordingly, a cinephotographic record was made of the tonic pupil before and after the procaine block. The left pupil of Case 2 was chosen as it became markedly reduced in size after the block. Illumination presented no problem, for this pupil did not react even to the brightest light. The patient was asked to look at a close object, and after the pupil showed no further constriction, she was told

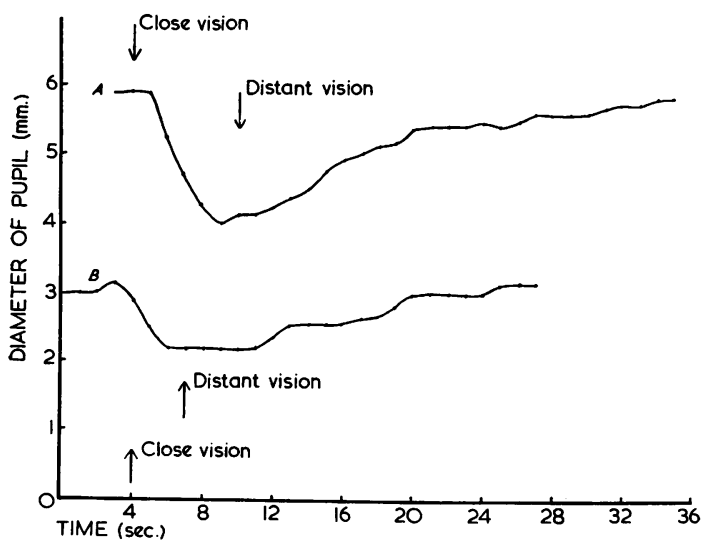

FIG. 2A.-Response of the pupil before stellate ganglion block; there is a delay of $23 \mathrm{sec}$. for return to resting size after accommodation.

FIG. 2B.-Response of the pupil after stellate ganglion block; the rate of dilatation remains unaltered. to look at the reflection of a distant light in a mirßor placed close to the camera lens. The film was exposied at a rate of 16 frames per second, so that the time taken by these pupillary movements could be measured wifh great accuracy. Fig. 2 shows the response of this pupil to accommodation before and after the sympathepic block, the amplitude of contraction becoming reduged from $1.9 \mathrm{~mm}$. to $0.9 \mathrm{~mm}$. The time taken for subsequent return to resting size was 23 seconds in 西e first instance, and 13 seconds after stellate ganglion block. When these values are equated with the reduced rapge of movement, it is seen that there is no alteration in the speed of pupillary relaxation; this is also borne out क्षेy the comparable slopes of the two curves.

The Conjunctival Instillation of Drugs.-Two drops of the chosen solution were instilled from the same ungraduated dropper into each eye. By this method the reaction of the two pupils could be compared, which $\overrightarrow{v a s}$ of great value when one of the pupils was normal.

Drugs with a Sympathetic Action.-Cocaine hyd $\overline{\text { s. }}$ chloride (3\%) and adrenaline hydrochloride $(0.1 \%)$ were used as a further test of sympathetic function. Jaffe (1950) has shown that with sympathectomized pupils the mydriatic effect of cocaine is lost as long as the sfle of the lesion is outside the central nervous systen. can be seen from Table I, cocaine caused a normal mydriatic response in every instance except in Cose9, where further dilatation was not possible, and in Case.34 where there was a known sympathetic defect. 尺Thtris effect was not excessive, however, for when the affered pupil was smaller than its normal or relatively nornal fellow, this relation of size remained unaltered (Tab\& $\mathbf{H}$ ). Jaffe also claims that in the presence of a post-gangtho sympathetic lesion, instilled adrenaline causes pupinilary dilatation. No such reaction was found in any of the cases.

TABLE II

COMPARISON OF THE EFFECT OF DRUGS BETWEEN TGE

\begin{tabular}{|c|c|c|c|c|}
\hline \multirow[b]{2}{*}{ Case } & \multicolumn{2}{|c|}{ Cocaine $3 \%$} & \multicolumn{2}{|c|}{ Homatropine $\frac{1}{2} \%$ O } \\
\hline & $\begin{array}{c}\text { Abnormal } \\
\text { Pupil } \\
\text { (mm.) }\end{array}$ & $\begin{array}{l}\text { Normal or Less } \\
\text { Affected Pupil } \\
\quad(\mathrm{mm} .)\end{array}$ & $\begin{array}{c}\text { Abnormal } \\
\text { Pupil } \\
\text { (mm.) }\end{array}$ & $\begin{array}{l}\text { Normal or Le⿳⺈⿴囗十 } \\
\text { Affected Punf } \\
\quad(\mathrm{mm} .)\end{array}$ \\
\hline $\begin{array}{r}3 \\
4 \\
5 \\
6 \\
12\end{array}$ & $\begin{array}{c}4 \rightarrow 5 \\
4 \frac{1}{2} \rightarrow 5 \frac{1}{2} \\
3 \frac{1}{2} \rightarrow 4 \frac{1}{2} \\
3 \rightarrow \rightarrow 4 \frac{1}{2} \\
4 \rightarrow 5 \frac{1}{2}\end{array}$ & $\begin{array}{l}3 \frac{1}{2} \rightarrow 6 \\
5 \rightarrow 6 \\
5 \frac{1}{2} \rightarrow 6 \frac{1}{2} \\
3 \frac{1}{2} \rightarrow 4 \frac{1}{2} \\
5 \frac{1}{2} \rightarrow 7\end{array}$ & $\begin{aligned} 4 \frac{1}{1} & \rightarrow 7 \\
4 \frac{1}{2} & \rightarrow 5 \frac{1}{2} \\
3 \frac{1}{2} & \rightarrow 5 \\
& = \\
3 \rightarrow 5 & \rightarrow \frac{1}{2}\end{aligned}$ & $\begin{array}{r}7 \rightarrow 8 \\
5 \frac{1}{2} \rightarrow 7 \\
4 \frac{1}{2} \rightarrow 7 \\
5 \frac{1}{2} \rightarrow 7\end{array}$ \\
\hline
\end{tabular}

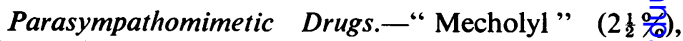
pilocarpine nitrate $(1 \%)$, and eserine sulphate $(0.25 \%)$, in the given concentrations, cause various responses $\exists$ n the normal eye. Eserine produces a maximal pupillagy contraction, whereas " mecholyl" (acetyl B methyl choline) is without any effect; pilocarpine occupies gn $^{n}$ intermediate position.

When tested on the abnormal pupil, these substandes showed the same relative potency, but the resultimg miosis varied greatly from case to case.

$N$

The response to eserine was of particular interest.9n Case 2, where the markedly tonic left pupil was conpared with the right one, unaffected at the time. 


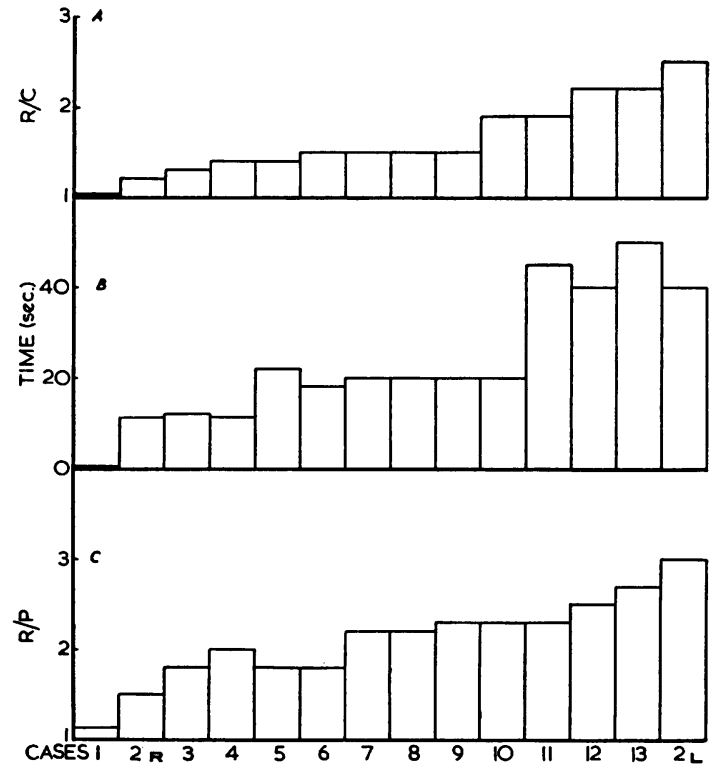

FIG. 3A.-R/C is the value of the fraction Size of pupil at rest

Size of pupil on convergence

(i.e., index of remaining parasympathetic function.)

FIG. 3B.-Time (sec.) taken for relaxation of pupil after constriction.

FIG. $3 C .-R / P$ is the value of the fraction

Size of pupil at rest

$\overline{\text { Size of pupil after pilocarpine }}$

(i.e., index of sensitivity.)

The cases are graded according to the degree of remaining parasympathetic function ( $A=$ greatest on the right, and least on the left), which is proportionate to the delay in relaxation (B) and the sensitivity of the pupil (C).

the right side a constriction from 3 to $2 \mathrm{~mm}$. was obtained, whereas the left pupil, initially the larger, became reduced from $7 \frac{1}{2}$ to $1 \frac{1}{2} \mathrm{~mm}$. within half an hour, and this miotic effect persisted after the right pupil had returned to its resting size. In addition, spasm of accommodation occurred on the left side only, with resulting ocular pain and blurring of vision, the visual acuity changing from J.1 to J.8. In contrast, a concentration of $0.5 \%$ eserine was required to cause constriction of the pupil in Case 1 from 9 to $4 \mathrm{~mm}$.

The action of " mecholyl " was tested in 19 abnormal pupils. In 14 of these, pupillary constriction resulted as shown in Table I, but five pupils remained unaltered in size. Again, there was a marked variation in the effect of pilocarpine, from an absence of any response to a marked sensitivity, which was assessed by comparing the resting size of the pupil with that after maximal constriction (Table I and Fig. 3). Increased sensitivity is denoted by high values of the fraction

Size of the pupil at rest

Minimal size of the pupil after pilocarpine

This index of sensitivity is reliable only in cases where the pupil's reaction to light is absent or sluggish; otherwise uncontrolled variations in illumination alter its value.

Homatropine Hydrobromide (0.5\%).-Moore (1931) states that pupillary dilatation to atropine is always full in the Holmes-Adie syndrome, in contrast with the incomplete effect of the drug on the Argyll-Robertson pupil. Alajouanine and Morax go further and say that the pupillary dilatation to homatropine is precocious and excessive. However, when a weak solution of homatropine was used in this series, the relationship of size between the pupils was preserved as a rule. Where the abnormal or more severely affected pupil was originally enlarged, dilatation was full, but where it was the smaller of the two, it did not reach full mydriasis with this concentration of the drug (Table II).

\section{Discussion}

The Functional Disturbance in the Holmes-Adie Pupil.-In considering the pathogenesis of the lesion, the relative role of the sympathetic and parasympathetic must be assessed.

(1) The Sympathetic Innervation of the Pupil.Several writers, including Adie, hold that at least some of the clinical features of the syndrome can be attributed to excessive or deficient sympathetic action. Most support is given to the theory of overaction of the sympathetic nerves in various sites (Garcin and Kipfer, 1936; Lowenstein and Friedman, 1942). It was to test this theory that studies were made by means of procaine block of the stellate ganglion.

The effect of a temporary interruption of the sympathetic on pupillary size varied from a marked miosis in Case $2 \mathrm{~L}$ to a lack of any demonstrable constriction in Case 1. The pupil was therefore kept enlarged by sympathetic activity only in certain cases; where the dilatation remained virtually unaltered after stellate ganglion block, a different mechanism must have been involved. Further observations were made on the tonic reaction of the pupil under conditions of sympathetic block. It was noted that a certain reduction occurred in the time taken for this reaction, but the point at issue was whether any change took place in the actual rate of pupillary constriction and dilatation over what had become a smaller range of movement. Cine/photographic measurements in Case 2L showed that this rate remained virtually unaltered after the block (Fig. 2). In other words, the sympathetic innervation is not responsible for the speed of pupillary movement, but partially governs the total time taken for relaxation by controlling the degree of dilatation.

The opposing view of sympathetic insufficiency has been held by other authors. Alajouanine and 
Morax (1938) attribute the excessive lability of the tonic pupil to its liberation from nervous control, sympathetic as well as parasympathetic. The occasionally associated ptosis (Alajouanine and Morax; Moore, 1931) seems to favour their view. Moreover, Graveson (1949) tentatively turns to such an explanation for the not infrequent finding of normal-sized or even miotic pupils. McKinney and Frocht (1940) and Scheie (1940) maintain, however, that the pupillo-dilator mechanism is intact, and confirmation of this is afforded by the present investigation.

In the first place, procaine block of the stellate ganglion resulted in pupillary constriction in every case where such constriction was possible (as shown by a preserved reaction to convergence). Secondly, the reaction of the pupil to cocaine and to adrenaline eye-drops remained normal. These two results provide ample proof of remaining sympathetic function, and were obtained with even the smallest pupils in the series (Cases $4,5,6,7,12$, and 13). The only exception was Case 14 , where ptosis and facial anhidrosis were present on the side of the tonic pupil. There the sympathetic lesion affected the sweat fibres and must, therefore, have involved the pathways proximal to the bifurcation of the common carotid artery-probably preganglionic fibres. In fact, this patient presented a picture similar to that obtained after stellate ganglion block in the other cases. Possibly this is a coincidental association of the tonic pupil and Horner's syndrome, since ptosis is a rare finding, and facial anhidrosis has never been described in the Holmes-Adie syndrome.

(2) The Parasympathetic Innervation of the Pupil.Most workers agree that a parasympathetic lesion is at least partly responsible for the clinical features of the pupillary abnormality (Behr, 1921; Adie, 1932; McKinney and Frocht, 1940; Scheie, 1940; and Leathart, 1942). Thus the usual absence of the reaction to light and the impairment of the reaction to convergence can be ascribed to such a lesion, and the slow constriction of the tonic pupil may also be a result of parasympathetic weakness.

From what has already been said, it can be understood why the pupil often fails to contract fully on convergence. Not infrequently, however, the paradoxical situation arises in which the constriction is greater than normal, or " tonic" in character, and it may be accompanied by spasm of accommodation when this function is also affected (Reitsch, 1925; Holmes, 1931; Alajouanine and Morax, 1938). Slowness of constriction can be explained by parasympathetic weakness, but another cause must be sought for the occasional excessive amplitude of the movement. The answer is provided by observi遮g the reaction of the pupil to drugs.

In his classical account, Adie stated that eserme and mydriatics were normal in their action. APajouanine and Morax, on the other hand, reported precocious or exaggerated reaction to a variety @f pharmacological agents, including eserine, pi carpine, cocaine, and homatropine. In the present studies, cocaine and adrenaline were normal in their effect, and homatropine dilated the pupil, not excessively. Evidence of sensitivity of the abnormal pupil to the cholinergic drugs was son etimes noted; for example, pupillary constriction ws sometimes excessive in amplitude or persisted und long, so that the abnormal pupil, usually the larger, became the smaller of the two. It must be pointed out, however, that this sensitivity was not always evident. The reaction to pilocarpine was the easiest to assess, and the index of sensitivity, as expressed by the ratio

Size of the pupil at rest

Minimal size of the pupil after pilocarpine

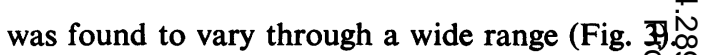

The most striking fact which emerges is that ofle is an approximate correlation between the degree of sensitivity to pilocarpine, the residual parasympathetic function and the time taken or pupillary relaxation. In other words, sensitivity so the cholinergic drug was found to be greatest whe the "tonic" reaction was most obvious, the fen " tonic" referring to both the range of moven ent and its delay. Conversely, where pupillary parefs and the parasympathetic lesion were markeg, sensitivity was slight or absent.

The Site of the Lesion. - The lesion in the HolmesAdie syndrome has been variously attributed to following sites: (1) Proprioceptive fibres from Re iris (Langworthy and Ortega, 1943); (2) the hypthalamus (Kennedy and others, 1938); (3) supganuclear ocular fibres (Lowenstein and Friedman, 1942). However, no lesion outside the efferent pathway of the light reflex could explain the loss of the direct reaction to light in a unilateral to pupil, with preservation of the indirect reaction: in the normal pupil. The lesion must therefore somewhere in the efferent pathway.

The apparent paradox of paresis and tonic reaction occurring in the same pupil can be explained לुy reference to the work of Cannon and Rosenblueth (1949) on the supersensitivity of denervated strectures. Their law states that when a chain of neurows is severed, there results, after an interval, a supôsensitivity of the distal elements and effectors ito the action of nerve impulses, and to certain chemißal 
agents either injected parenterally or applied locally. Shen and Cannon (1936) performed a unilateral excision of the ciliary ganglion in the cat, and demonstrated that, after an interval of a few days, a locally instilled solution of acetyl choline caused a maximal contraction of the iris. This response of the iris to acetyl choline after a parasympathetic lesion is analogous to the sensitivity of sympathectomized structures to adrenaline. Although the practical importance of this phenomenon after surgical procedures in man has been exaggerated, as pointed out by Learmonth (1950), its occurrence during disease processes has not received the attention it deserves. It would certainly account for the pupillary abnormalities in the Holmes-Adie syndrome.

In the first place, it would explain why the iris becomes sensitive to cholinergic drugs. There are two possible ways in which this sensitivity develops: a deficient formation of cholinesterase may impair the removal of acetyl choline, or the effector cells of the sphincter pupillae may react to the drug in an exaggerated fashion. Both mechanisms probably operate, but the latter is the more important in view of the overaction to drugs such as pilocarpine, which are unaffected by cholinesterase.

Secondly, a comparison may be made with the Philipeaux-Vulpian phenomenon in which, as a result of stimulating the chorda tympani, a contraction of the tongue is obtained some days after the hypoglossal nerve has been sectioned. This pseudo-motor effect is thought to be the result of a diffusion of acetyl choline from the stimulated autonomic nerve endings to the denervated and sensitized striated muscle fibres (Cannon and Rosenblueth, 1949). The contraction is often slow and excessive-in fact, very much like that found in the tonic pupil. There acetyl choline presumably diffuses from intact parasympathetic nerve endings to denervated and sensitized smooth muscle fibres of the pupillary sphincter. This explanation is also offered by Scheie (1940) who thinks that all these pupils are hypersensitive to the cholinergic drug he used, namely, "mecholyl ". Supersensitivity is not invariably found, however, and it decreases when the parasympathetic lesion increases. It is precisely in such pupils that the tonic reaction is absent or slight, probably because little or no acetyl choline is liberated. Hence these features are absent in cases with ophthalmoplegia interna, a not uncommon manifestation of the Holmes-Adie syndrome.

In conclusion, the presence of pupillary paresis, with accompanying hypersensitivity to cholinergic drugs, places the site of the disturbance along the parasympathetic pathway between the third nerve nucleus and the short ciliary nerves. Whether the pre- or the post-ganglionic nerves are primarily affected remains uncertain, but there is some evidence in favour of the latter. In lesions of the sympathetic nervous system, sensitivity is usually more marked after post-ganglionic than after preganglionic denervation, but Keil and Root (1942) point out that with parasympathetic denervation of the cat's iris the two different sections are often equal in their effect. On the other hand, there are records of tonic pupils developing after injuries or tumours established as affecting the ciliary ganglion or short ciliary nerves (Axenfeld, 1906; Ohm, 1907; Cords, 1930; Garcin and Kipfer, 1936). Moreover, the constant irregularity of the pupil points to a selective segmental denervation, such as would be produced by patchy involvement of the short ciliary nerves. The ciliary ganglion is thought to be the site of the lesion by Magitot (1911), Scheie (1940), and Leathart (1942), whereas Behr (1921) and Adie (1932) suggest that the third nerve nucleus is implicated. This concept of sensitization to the effect of acetyl choline is quite distinct from Saenger's theory of a primary muscular abnormality independent of denervation (1902), for which there is no supporting evidence.

Classification of the Abnormal Pupil.-Many variants of the tonic pupil are recognized in clinical practice, and for the purposes of classification some unifying theme is needed. Adie recognizes "atypical" pupils, the term being used to include pupils which are fixed. This is criticized by McKinney and Frocht (1940) on the grounds that confusion may arise with other causes of ophthalmoplegia interna, including syphilis. Nevertheless, most authors accept these divergencies from the classical appearances, and Graveson divides his cases into those with "fixed" and those with " ordinary" types of pupil.

It must be accepted, moreover, that Holmes-Adie pupils are seldom identical, and that there are innumerable variations between the forms which I shall term "paralytic" and truly " tonic". The variations depend on the severity of the lesion and on its duration, since the degree of paralysis or sensitization of the sphincter muscle of the iris is determined by these two factors. When the parasympathetic fibres have been recently and completely destroyed, the pupil fails to constrict on convergence, does not become miotic after stellate ganglion block, and is not supersensitive to cholinergic drugs. The tonic pupil, on the other hand, is found some time after a lesser degree of parasympathetic damage; the pupil responds more fully to convergence and 
sympathetic denervation, and a slow contraction and relaxation are evident, together with an enhanced response to the parasympathomimetic drugs. It must be pointed out that the enlargement of the pupil, commonly encountered, does not necessarily indicate that the defect is mainly one of paralysis. Two of the largest pupils in this series (Cases $2 \mathrm{~L}$ and 11) were remarkably tonic in their response, and became exceedingly small on stellate ganglion block, indicating that their size was maintained by sympathetic activity. It is interesting to note that in one patient (Case 2) both pupils were dilated, the right being "paralytic" in type and the left " tonic".

Finally, the evolution of the disturbance can be understood in terms of either a development of sensitivity or a recurrence of paralysis. The first manifestation of the disease, and it must be called a disease, is usually the appearance of a " paralytic" type of pupil. In time, if the damage has been only partial, some tonicity appears. Relapse may occur after an interval of months or years, but this is usually in the other eye. Adie does state that the tonic reaction may subsequently disappear, but this has not been observed by others (Alajouanine and Morax, 1938). Theoretically, there is no reason why such a recrudescence should not take place on the same side. The associated defect of accommodation has the same natural history: paralysis, with recession of the near point, is followed by delayed contraction of the ciliary muscle and slowing of accommodation. When the ciliary muscle is affected, its involvement is usually simultaneous with that of the sphincter pupillae, but is of a different degree. The tendon reflexes may be involved at any stage of the clinical course.

\section{Summary}

Fourteen cases of the Holmes-Adie syndrome are reviewed, and an attempt is made to clarify the pathogenesis of the pupillary disturbance by studying the effect of stellate ganglion block and of the conjunctival instillation of drugs. The main defect is one of parasympathetic denervation, the syme pathetic remaining intact. The tonic contractiog and delayed relaxation indicate supersensitization of the denervated sphincter pupillae to acetyl choline liberated by intact parasympathetic fibres.

The lesion is in the efferent parasympathetic pathway, and is probably post-ganglionic.

Depending on the respective degree of paralyst and supersensitization, wide clinical variations ma be met, but two broad types are recognized 0 "paralytic" and "tonic". The natural histor of the disease may be one of repeated episode? affecting the pupils, the function of accommodations and the tendon reflexes in turn.

I wish to thank Dr. John Marshall for encouragement with this work, and Drs. J. B. Stanton and E. B. French? Prof. Sir Stanley Davidson, and Prof. J. W. Crofton for granting me access to patients under their care.

\section{REFERENCES}

Adie, W. J. (1932). Brain, 55, 98 . V. (1938). Ann. Oculist (Paris) 175,205 .

Axenfeld, T. (1906). Dtsch. med. Wschr., 32, 663.

Axenig). Klin. Mbl. Augenheilk., 62, 59.

Barré, J. A., and Klein, M. (1934). Rev. neurol (Paris), 1, 590 이 Behr, C. (1921). Klin. Mbl. Augenheilk., 66, 770. Cannon, W. B., and Rosenblueth, A. (1949). The Supersensitivi Cords, R. (1930). Zbl. ges. Neurol. Psychiat., 55, 701.

Cords, R. (1930). Zbl. ges. Neurol. Psychiat., 55, 701. Garcin, R., and Kipfer, M. (1936). Rev, neurol. (Paris), 65, 128
Graveson, G. S. (1949). Journal of Neurology, Neurosurgery and Psychiatry, 12, 219.

Holmes, G. (1931). Trans. ophthal. Soc. U.K., 51, 209.

Jaffe, N. S. (1950). Arch. Ophthal. (Chicago), 44, 710.

Keil, F. C., and Root, W. S. (1942). Amer. J. Physiol., 136, 173

Kennedy, F., Wortis, H., Reichard, J. D., and Fair, B. B. (18)

Arch. Ophthal. (Chicago), 19, 68.
Langworthy, O. R., and Ortega, L. (1943). Medicine (Baltimores $22,287$.

Learmonth, J. R. (1950). Lancet, 2, 505.

Leathart, P. W. (1942). Brit. J. Ophthal., 26, 60. Leathart, P. W. (1942). Frit. J. Ophthal., 26, 60. (1942). Arch. Ophtha年
(Chicago), 28, 1042.

McKinney, J. M., and Frocht, M. (1940). Amer. J. med. Sct居

Magitot, A. (1911). Ann. Oculist (Paris), 145, 258.

Moore, D. C. (1954). Stellate Ganglion Block. Charles C. Thoma Springfield, Illinois.

Moore, R. F. (1931). Trans. Ophthal. Soc. U.K., 51, 203.

Ohm, J. (1907). Zbi. prakt. Augenheilk., 31, 193.

Reitsch, W. (1925). Klin. Mbl. Augenheilk., 74, 159.

Rothmann, M. (1903). Neurol. Zbl., 22, 242.

Saenger, A. (1902). Ibid., 21, 837 and 1137.

Scheie, H. G. (1940). Arch. Ophthal. (Chicago), 24, 225.

Shen, S. C., and Cannon, W. B. (1936). Chin. J. Physiol., 10, 35 